\title{
North Australian Sea Surface Temperatures and the El Niño-Southern Oscillation in the CMIP5 Models
}

\author{
JENNIFER L. CATTO AND NEVILlE NiCHOLlS \\ School of Geography and Environmental Science, Monash University, Melbourne, Australia \\ CHRISTIAN JAKOB \\ School of Mathematical Science, Monash University, Melbourne, Australia
}

(Manuscript received 16 April 2012, in final form 9 July 2012)

\begin{abstract}
Aspects of the climate of Australia are linked to interannual variability of the sea surface temperatures (SSTs) to the north of the country. SST anomalies in this region have been shown to exhibit strong, seasonally varying links to ENSO and tropical Pacific SSTs.

Previously, the models participating in phase 3 of the Coupled Model Intercomparison Project (CMIP3) have been evaluated and found to vary in their abilities to represent both the seasonal cycle of correlations between the Niño-3.4 and north Australian SSTs and the evolution of SSTs during composite El Niño and La Niña events. In this study, the new suite of models participating in the CMIP5 is evaluated using the same method. In the multimodel mean, the representation of the links is slightly improved, but generally the models do not capture the strength of the negative correlations during the second half of the year. The models also still struggle to capture the SST evolution in the north Australian region during El Niño and La Niña events.
\end{abstract}

\section{Introduction}

The El Niño-Southern Oscillation (ENSO) is linked to the interannual climate variability of Australia, in part through its effect on the sea surface temperatures (SSTs) around northern Australia. The strong link between the observed SSTs in the Niño-3.4 region and the north Australian region has been documented by Hendon (2003) and more recently by Catto et al. (2012). This link is related to feedbacks between the SST anomalies due to ENSO and the seasonal cycle of zonal winds in the north Australian region (Hendon 2003; Zhong et al. 2005). It is important that global coupled climate models are able to represent this link between ENSO and north Australian SSTs so that we can have more confidence in the projections of future climate change for the Australian region. Recently, Catto et al. (2012) investigated the representation of this connection in the phase 3 of the Coupled Model Intercomparison

Corresponding author address: Jennifer Catto, School of Geography and Environmental Science, Monash University, Clayton Campus, Melbourne VIC 3800, Australia.

E-mail: jennifer.catto@monash.edu
Project (CMIP3) suite of climate models. While many of the models could represent the ENSO variability well, there was a wide range in the abilities of the models to capture the strong seasonal link between Niño-3.4 and north Australian SSTs.

A new suite of model simulations has been produced for CMIP5. The aim of the present study is to use the same methodology as Catto et al. (2012) to investigate the representation of the link between ENSO and north Australian SSTs in these new model simulations. An important question is whether the new generation of climate models have improved in their representation of this aspect of climate variability when compared against the CMIP3 models. It is not obvious that they should, as the measures considered here are demanding tests of the models and are not aspects of the climate that would be considered in the development of climate models, making them a good independent test of model performance. While the focus of the study is especially relevant for simulations of Australian climate, it may also be important for other aspects of ENSO simulation. After development of the CMIP3 models, AchutaRao and Sperber (2006) found improved simulation of many aspects of ENSO over the previous (CMIP2) collection of 
TABLE 1. Models used in this study.

\begin{tabular}{|c|c|}
\hline Model & Group \\
\hline ACCESS1.0 & $\begin{array}{l}\text { Australian Community Climate and Earth System Simulator, version } 1.0 \text { (ACCESS1.0), CSIRO } \\
\text { and Bureau of Meteorology (BoM), Australia }\end{array}$ \\
\hline ACCESS1.3 & $\begin{array}{l}\text { Australian Community Climate and Earth System Simulator, version } 1.3 \text { (ACCESS1.3), CSIRO } \\
\text { and BoM, Australia }\end{array}$ \\
\hline BCC CSM1.1 & $\begin{array}{l}\text { Beijing Climate Centre (BCC), Climate System Model version 1.1 (CSM1.1), } \\
\text { China Meteorological Administration }\end{array}$ \\
\hline CanESM2 & $\begin{array}{l}\text { Second generation Canadian Earth System Model (CanESM2), Canadian Centre for } \\
\text { Climate Modeling and Analysis }\end{array}$ \\
\hline CCSM4 & Community Climate System Model, version 4 (CCSM4), NCAR, United States \\
\hline CESM1-CAM5 & $\begin{array}{l}\text { Community Earth System Model, Community Atmosphere Model version } 5 \\
\text { (CESM1-CAM5), NCAR, United States }\end{array}$ \\
\hline CESM1-FASTCHEM & Community Earth System Model with FASTCHEM (CESM1-FASTCHEM), NCAR, United States \\
\hline CMCC-CM & Centro Euro-Mediterraneo per I Cambiamenti Climatici (CMCC) Climate Model (CM), Italy \\
\hline CNRM CM5 & $\begin{array}{l}\text { Centre National de Recherches Météorologiques (CNRM) Global Climate Model version 5, } \\
\text { CNRM/Centre Europeen de Receherche et Formation Avancees en Calcul Scientifique, France }\end{array}$ \\
\hline CSIRO MK3.6 & CSIRO in collaboration with Queensland Climate Change Centre of Excellence, Australia \\
\hline EC-Earth & EC-Earth Consortium \\
\hline FIO-ESM & First Institute of Oceanography (FIO) Earth System Model (ESM), SOA, China \\
\hline GFDL CM2.1 & $\begin{array}{l}\text { Geophysical Fluid Dynamics Laboratory (GFDL) Climate Model version 2.1, NOAA GFDL, } \\
\text { United States }\end{array}$ \\
\hline GFDL CM3 & GFDL Climate Model version 3, NOAA GFDL, United States \\
\hline GFDL ESM2G & GFDL Earth System Model with GOLD ocean component (ESM2G), NOAA GFDL, United States \\
\hline GFDL ESM2M & GFDL Earth System Model with MOM4 ocean component (ESM2M), NOAA GFDL, United States \\
\hline GISS E2H & $\begin{array}{l}\text { Goddard Institute for Space Science (GISS) ModelE with Hycom Ocean (E2H), NASA GISS, } \\
\text { United States }\end{array}$ \\
\hline GISS E2R & GISS ModelE with Russell Ocean (E2R), NASA GISS, United States \\
\hline HadCM3 & Met Office Hadley Centre Climate Model version 3, United Kingdom \\
\hline HadGEM2-AO & $\begin{array}{l}\text { Met Office Hadley Centre Global Environment Model version } 2 \text { (Atmosphere and Ocean) } \\
\text { (GEM2-AO), United Kingdom }\end{array}$ \\
\hline HadGEM2-ES & $\begin{array}{l}\text { Met Office Hadley Centre Global Environment Model version } 2 \text { (Earth System) (GEM2-ES), } \\
\text { United Kingdom }\end{array}$ \\
\hline HadGEM2-CC & $\begin{array}{l}\text { Met Office Hadley Centre Global Environment Model version } 2 \text { (Carbon Cycle) (GEM2-CC), } \\
\text { United Kingdom }\end{array}$ \\
\hline INM-CM4 & Institute for Numerical Mathematics (INM) Coupled Model version 4 (CM4), Russia \\
\hline IPSL CM5A-LR & $\begin{array}{l}\text { L'Institut Pierre-Simon Laplace (IPSL) Coupled Model version 5A Low Resolution } \\
\text { (CM5A-LR), France }\end{array}$ \\
\hline IPSL CM5A-MR & IPSL Coupled Model version 5A Mid Resolution (CM5A-MR), IPSL, France \\
\hline IPSL CM5B-LR & IPSL Coupled Model version 5B Low Resolution (CM5B-LR), IPSL, France \\
\hline MIROC5 & $\begin{array}{l}\text { Model for Interdisciplinary Research on Climate (MIROC) version 5, Atmosphere and } \\
\text { Ocean Research Institute (the University of Tokyo), National Institute for Environmental Studies, } \\
\text { and Japan Agency for Marine-Earth Science and Technology, Japan }\end{array}$ \\
\hline MPI ESM LR & Max Planck Institute (MPI) Earth System Model (Low Resolution) (ESM LR), MPI, Germany \\
\hline MPI ESM MR & MPI Earth System Model (Medium Resolution) (ESM MR), MPI, Germany \\
\hline MPI ESM P & MPI Earth System Model (Paleo) (ESM P), MPI, Germany \\
\hline MRI CGCM3 & Meteorological Research Institute (MRI) Coupled General Circulation Model, version 3 (CGCM3), Japan \\
\hline NorESM1-M & Norwegian Climate Centre Earth System Model version 1 (Medium Resolution) (NorESM1-M), Norway \\
\hline
\end{tabular}

models (AchutaRao and Sperber 2002). Early evaluation of the CMIP5 models by Guilyardi et al. (2012) indicated improvements in some aspects of ENSO simulation in models contributed by some modeling groups.

Section 2 briefly describes the data and analysis method used. Section 3 looks at the representation of the link between ENSO and north Australian SSTs in the CMIP5 models and how they compare to the CMIP3 models, and a summary is given in section 4 .

\section{Data and methods}

As in Catto et al. (2012), the observational dataset that has been used to assess the models is the Hadley Centre Global Sea Ice and Sea Surface Temperature (HadISST) dataset (Rayner et al. 2003). Monthly-mean SSTs from 1950 to 1999 have been used to provide the observationally constrained data against which to compare the models.

The simulations performed recently as part of CMIP5 and available on the Earth System Grid (ESG) data 
archives have been used in this study and are listed in Table 1 along with their acronyms and identifiers. Similar to the CMIP3 project, simulations using recent historical forcings have been performed; this experiment is referred to as "historical" (Taylor et al. 2012). The 50-yr period from 1950 to 1999 has been used to compare against the HadISST data.

Two SST indices have been used which were calculated from monthly-mean SST values from HadISST and from the CMIP5 models. The first is the Niño-3.4 index (the average from a box $5^{\circ} \mathrm{S}-5^{\circ} \mathrm{N}$ and $170^{\circ}-120^{\circ} \mathrm{W}$ ), and the second is the north Australian SST index $\left(0^{\circ}-15^{\circ} \mathrm{S}\right.$ and $\left.110^{\circ}-150^{\circ} \mathrm{E}\right)$. The correlation between these two indices over the 50-yr period has been calculated for each month to give a seasonal cycle of the link between the two regions. Catto et al. (2012) showed that, using the HadISST data, the correlations are positive from January to April and then negative for the rest of the year, becoming most strongly negative in October. This indicates that during the latter part of the year, a warm anomaly in the Niño-3.4 region would coincide with a cold anomaly in the north Australian region and vice versa.

The other method of evaluating the link between the Niño-3.4 and north Australian regions that has been used is the compositing of individual El Niño and La Niña events. These events were identified in each of the datasets using the same simple automated method that was applied in Catto et al. (2012) using SST anomalies from the Niño-3.4 region. For events lasting longer than $1 \mathrm{yr}$, only the year in which the event first developed was used in the analysis. The composite SST evolution over the three years centered on the year of development (years $-1,0$, and 1) shows how the north Australian SST anomalies evolve along with the Niño-3.4 SSTs. In the HadISST data, six El Niño events and six La Niña events were identified and composited. During El Niño events, the north Australian SST anomalies exhibit a rapid change of sign in the austral spring of year -1 from positive to negative and then again in year 0 from negative to positive.

\section{Results}

In this section, the CMIP5 models are evaluated against HadISST for the measures discussed in the previous section and are compared against the results using the CMIP3 models, presented by Catto et al. (2012).

\section{a. Overview of CMIP5 model performance}

As a first evaluation of the models, the root-meansquare error (RMSE) of the time evolution of the monthly correlation coefficient between Niño-3.4 and north Australian SST is calculated. Similarly, the RMSE for the 3-yr evolution of the Niño-3.4 and north Australian SST anomaly for warm and cold events is calculated, leading to five RMSE error measures. The values for these errors as well as the respective rank of each model are shown in Fig. 1. Where there are a number of ensemble members for an individual model, the ensemble mean has been used. Figure 1 shows there is a range of values of RMSE from the different models (cf. Catto et al. 2012, Fig. 3). The CMIP5 models represent more closely these five measures compared to the CMIP3 models, because there are generally lower values of RMSE. In fact, the average values of RMSE for the different measures are lower for the CMIP5 models for all but the north Australian SSTs during La Niña events. This is the case whether using the ensemblemean values or a randomly chosen run. The Community Climate System Model, version 4 (CCSM4) is the best performing model on average over the five measures.

Many of the same modeling groups have contributed to both the CMIP3 and CMIP5 databases. In most cases, the groups have submitted simulations from newer versions of their models to CMIP5. Catto et al. (2012) found that, for the CMIP3 models, HadCM3 was the best performing model overall, and particularly for the seasonal cycle of correlations it performed very well. In the simulations provided for the CMIP5 comparison, HadCM3 still performs reasonably in terms of the composite SST evolution (ranked 2, 5, 4, and 11) but is ranked 19th for the seasonal cycle of correlations mainly because of the seasonal cycle being weaker than observed.

The average rank of CCSM4 is the highest for any of the models in CMIP5. The RMSE in CCSM4 has decreased for all measures from those for CCSM3, the CMIP3 contribution from the National Center for Atmospheric Research (NCAR). This is especially true for the SST evolution in the Niño-3.4 region and is likely related to changes to the deep convection scheme, which led to improvements in the model's ENSO period (Neale et al. 2008; Richter and Rasch 2008; Gent et al. 2011). Deser et al. (2012) also showed improvements in terms of the ENSO asymmetry between El Niño and La Niña events in CCSM4 compared to CCSM3.

The biggest improvement in models from particular groups can be seen in the models from the Goddard Institute for Space Studies (GISS; see also Grose et al. 2012, manuscript submitted to Climate Dyn.). In two out of three of this group's models contributing to CMIP3, there was very low tropical Pacific variability and no ENSO events identified. The two models contributing to CMIP5 (differing by their ocean models) have much better variability and have overall ranks of 11 and 18 in their ensemble means. One major difference in the GISS models from CMIP3 to CMIP5 is the large increase in resolution of both the atmosphere and ocean components. 


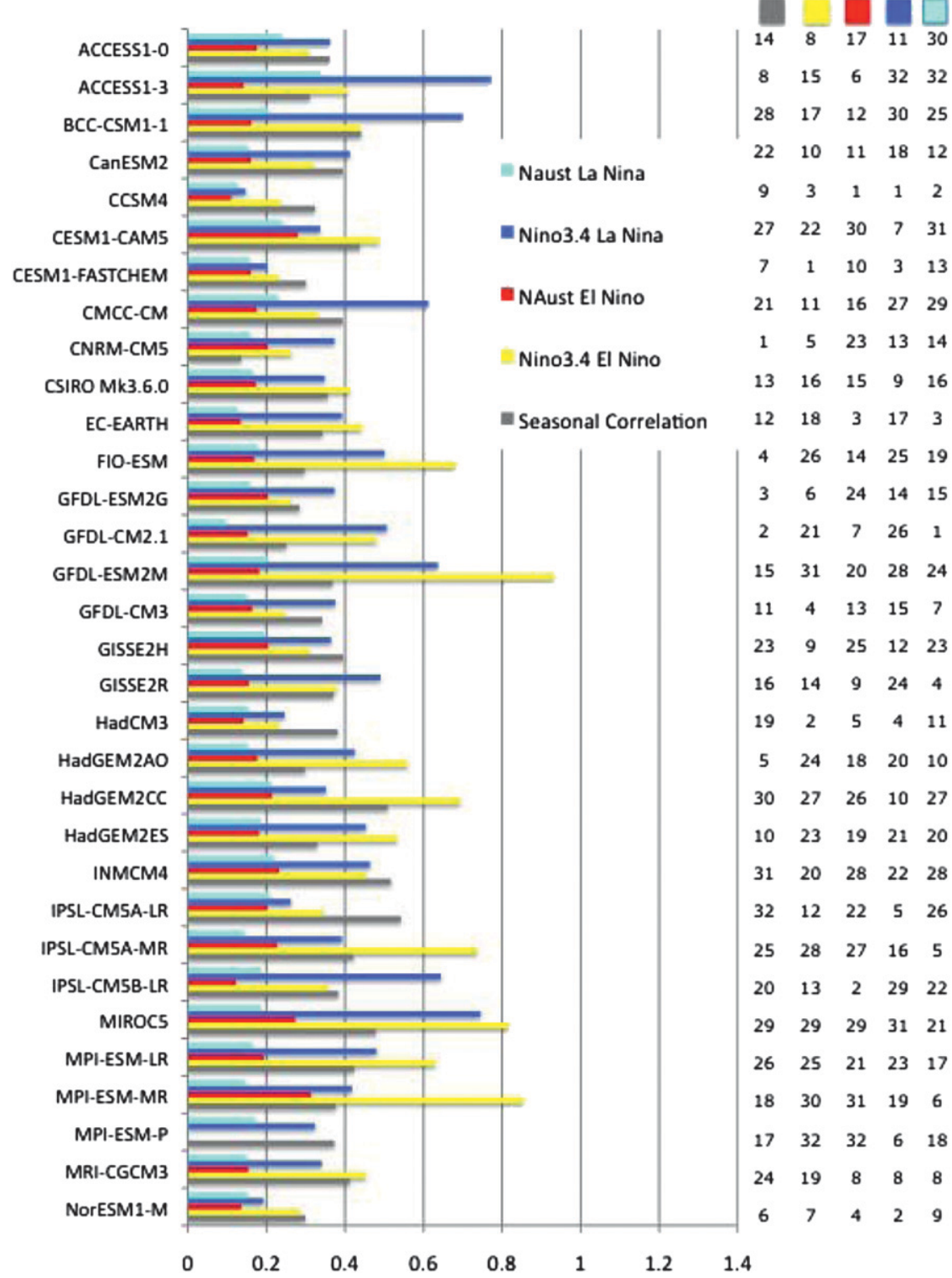

FIG. 1. RMSE for the correlations between Niño-3.4 and northern Australia indices, composite evolution of Niño-3.4 SSTs during El Niño events, and composite evolution of north Australian SSTs during El Niño events, in each of the CMIP5 models in the historical simulations (1950-99). The rank of each model (using the RMSE) for each of the measures is given on the right.

Four models were available for analysis from the Geophysical Fluid Dynamics Laboratory (GFDL), the Earth system models (ESM) with differing ocean formulations (ESM2G and ESM2M), and the two coupled general circulation models, Climate Model version 2.1 (CM2.1) and CM3. Both CM2.1 and CM3 have mixed results in terms of the different measures, and any differences between these two are attributable to the atmosphere component (Donner et al. 2011; Griffies et al. 2011), while differences between ESM2G and ESM2M are due only to the ocean component.
The version of the CNRM model used in CMIP5 (CNRM-CM5) shows much lower RMSE values for the seasonal cycle of correlations and the Niño-3.4 SST evolution during ENSO events but higher RMSE values for the north Australian SST evolutions. The new version of the CSIRO model (Mk3.6) shows similarly mixed changes when compared to the previous version (Mk3.5). This is also true for the two new IPSL models, which show both positive and negative changes to the RMSE values over the version used in CMIP3. Maury et al. (2012) show in the IPSL Coupled Model, 


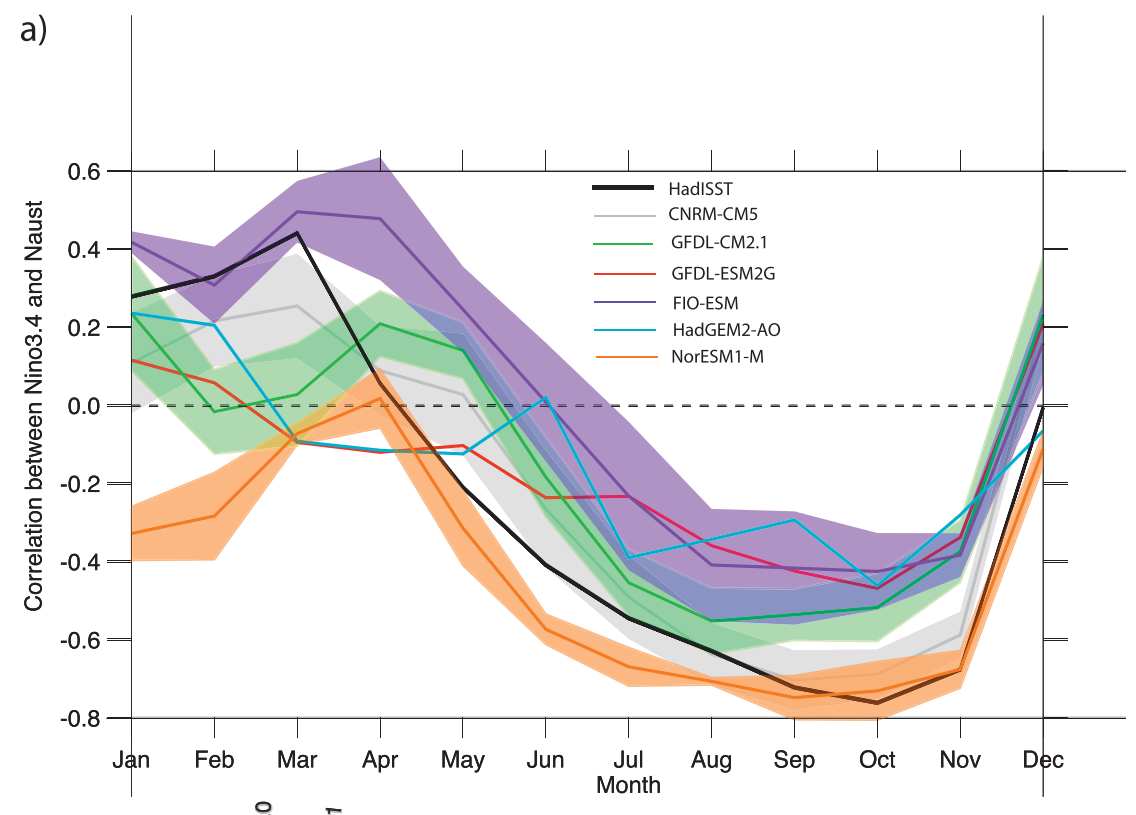

b)

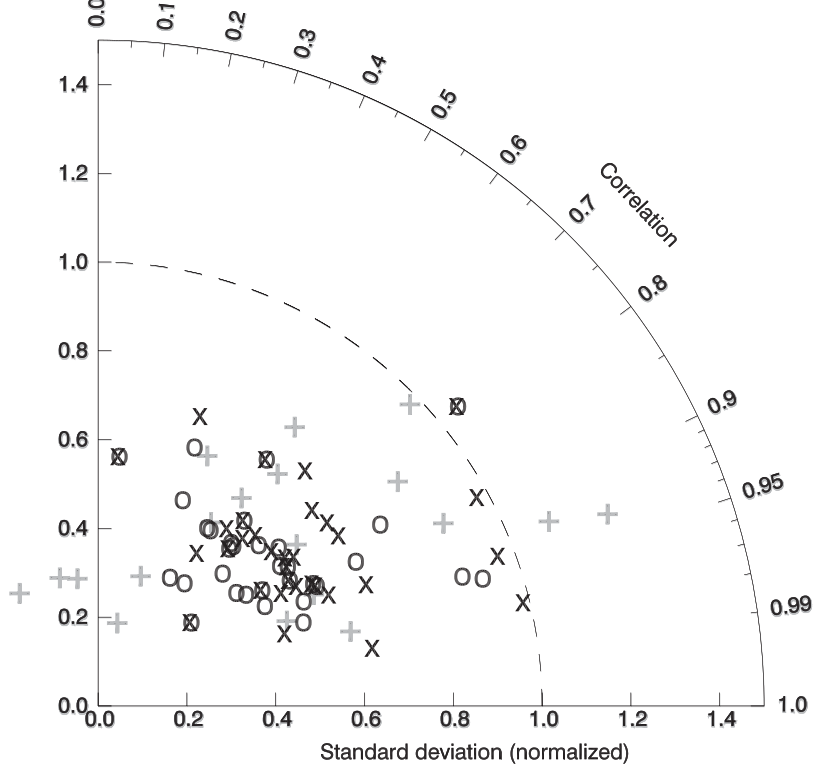

FIG. 2. (a) Monthly correlations between the Niño-3.4 and north Australian SST indices for detrended HadISST and the six CMIP5 models with the lowest RMSE values. The central line for each model shows the ensemble-mean value (for all ensemble members of that particular model), and the shading represents one standard deviation calculated from the ensemble. The GFDL ESM2G and HadGEM2-AO models have only one ensemble member. Correlations are significant at the $95 \%$ level for correlations exceeding a magnitude of 0.288 . (b) Taylor diagram for all CMIP3 and CMIP5 models. The gray plus signs are the CMIP3 models, the black crosses are the CMIP5 models using the best (lowest RMSE) ensemble member for each model, and the black circles are the ensemble mean for each CMIP5 model. Where the crosses and circles occur exactly together, there is only one ensemble member.

version 5 (CM5) preindustrial control runs that, although the amplitude of ENSO is represented well, the maximum variability occurs too far west in the Pacific, which would impact the links investigated here.
For CMIP5 there are three different versions of the Hadley Centre Global Environmental Model (HadGEM) available, the atmosphere-ocean model (HadGEM2AO), the Earth system model (HadGEM2-ES), and the atmosphere-ocean with carbon cycle model 
(HadGEM2-CC). HadGEM2-ES performs better for all the measures than HadGEM1, which was used in CMIP3, while HadGEM2-CC performs worse. HadGEM2-AO captures the seasonal cycle of correlations and the evolution of SSTs in the north Australian region better than the other two models, but the performance in capturing the Niño-3.4 SSTs is mixed. MIROC5 has higher values of RMSE for almost all measures compared to the two models contributing to CMIP3 MIROC 3.2, high-resolution version MIROC3.2(hires) and MIROC3.2, medium-resolution version [MIROC3.2 (medres)]; however, Kim et al. (2011) find improved ENSO amplitude in MIROC5 possibly due to improved convective parameterization.

\section{b. Seasonal cycle of correlations}

The seasonal cycle of correlations for the six models that perform best in terms of that measure are shown in Fig. 2a along with the HadISST data. Where the models have more than one ensemble member, the ensemble mean and the standard deviation of the ensemble are shown. Figure 2a shows that only two of the six best performing CMIP5 models capture the strong negative correlations in the second half of the year: namely, NorESM1-M and CNRM-CM5. For these two models, the standard deviations of their ensembles are small compared to the difference between them and the other models. The results for the ensemble mean are therefore fairly robust. CNRM-CM5 is able to consistently simulate the seasonal link between the north Australian and Niño-3.4 SSTs, while NorESM1-M simulates the strong link in the second half of the year only.

To compare the representation of the seasonal cycle of correlations in the CMIP5 models with those from CMIP3, Fig. 2b shows a Taylor diagram. The diagram contains entries for each of the CMIP3 models, the ensemble mean for each of the CMIP5 models, and the "best" ensemble member (judged using the RMSE) for the CMIP5 models. For some of the CMIP5 models there was only one ensemble member available, and in these cases the best member and ensemble mean are the same. Although the multimodel-mean RMSE for this measure suggests improvement over the CMIP3 models, judged by the Taylor diagram this seems to be due to only three or four models. The best CNRM-CM5 ensemble member from the CMIP5 simulations is the bestperforming model overall, and there are three other models with their best ensemble member lying very close to the observed standard deviation. However, while the CMIP3 models show a larger spread in the representation of the seasonal cycle of correlations, the CMIP5 models seem to be more similar to one another, with a clustering of the models on the Taylor diagram
TABLE 2. Ensemble average number of El Niño events and La Niña events detected in each of the models in the historical simulations (1950-99).

\begin{tabular}{|c|c|c|c|}
\hline Model & Runs & El Niño & La Niña \\
\hline HadISST & & 6 & 6 \\
\hline ACCESS1.0 & 1 & 5 & 4 \\
\hline ACCESS1.3 & 1 & 5 & 4 \\
\hline BCC CSM1.1 & 1 & 9 & 8 \\
\hline CanESM2 & 5 & 7.6 & 9.6 \\
\hline CCSM4 & 6 & 5.3 & 7.5 \\
\hline CESM1-CAM5 & 3 & 6.3 & 7 \\
\hline CESM1-FASTCHEM & 3 & 5.7 & 9 \\
\hline CMCC-CM & 1 & 3 & 2 \\
\hline CNRM-CM5 & 10 & 8.9 & 11.2 \\
\hline CSIRO Mk-3.6 & 10 & 3.2 & 4.6 \\
\hline EC-Earth & 11 & 0.5 & 6.7 \\
\hline FIO-ESM & 3 & 4.7 & 6.7 \\
\hline GFDL ESM2G & 1 & 2 & 5 \\
\hline GFDL ESM2M & 1 & 2 & 5 \\
\hline GFDL CM2.1 & 10 & 5.8 & 6.7 \\
\hline GFDL CM3 & 5 & 8.8 & 9.2 \\
\hline GISS E2H & 9 & 4.2 & 4.1 \\
\hline GISS E2R & 9 & 6 & 6.3 \\
\hline HadCM3 & 10 & 5.7 & 4.8 \\
\hline HadGEM2-AO & 1 & 2 & 3 \\
\hline HadGEM2-CC & 1 & 4 & 6 \\
\hline HadGEM2-ES & 4 & 4.25 & 1.5 \\
\hline INM-CM4 & 1 & 2 & 3 \\
\hline IPSL CM5A-LR & 5 & 5.6 & 3.4 \\
\hline IPSL CM5A-MR & 1 & 5 & 6 \\
\hline IPSL CM5B-LR & 1 & 7 & 4 \\
\hline MIROC5 & 4 & 1.25 & 4 \\
\hline MPI ESM LR & 3 & 0.7 & 2.3 \\
\hline MPI ESM MR & 3 & 1 & 3.7 \\
\hline MPI ESM P & 2 & 0 & 3 \\
\hline MRI CGCM3 & 5 & 2.4 & 2.6 \\
\hline NorESM1-M & 3 & 6 & 8 \\
\hline
\end{tabular}

in a region of lower than observed standard deviation, indicating weaker annual cycles of the correlation.

\section{c. Composite ENSO evolution}

Individual El Niño and La Niña events were identified using the method described briefly in section 2 and in more detail in Catto et al. (2012). The ensemble-mean numbers of events from each of the CMIP5 models are given in Table 2. Many of the models have good SST tropical Pacific variability compared to the HadISST dataset, but there are a number models in which very few events can be identified: for example the Max Planck Institute (MPI) ESMs and the GFDL ESMs.

Taylor diagrams showing the representation of the composite ENSO SST evolution for the two different regions are presented in Fig. 3. As in Fig. 2b, both the CMIP3 and CMIP5 models are shown. First considering the Niño-3.4 SSTs during El Niño events (Fig. 3a), the CMIP5 models have a much smaller spread in their 
a)

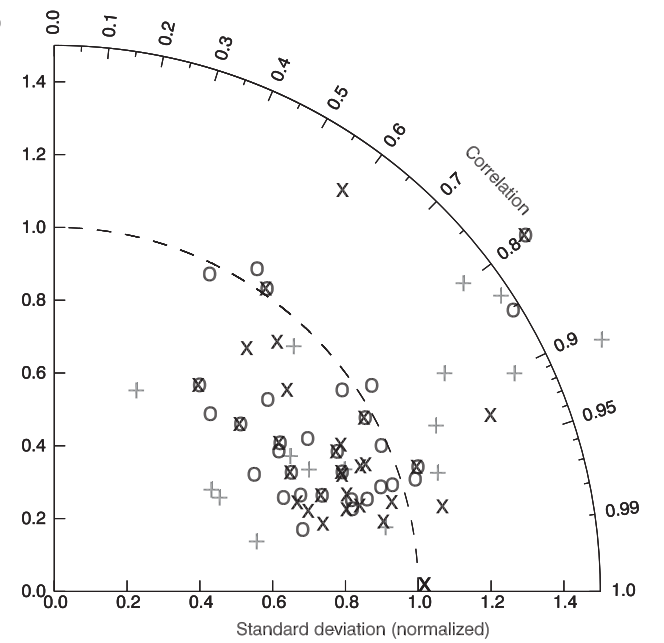

c)

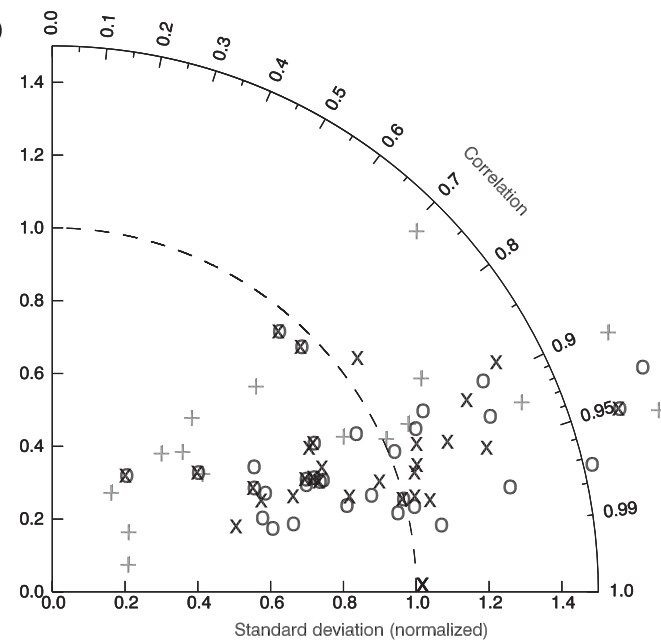

b)

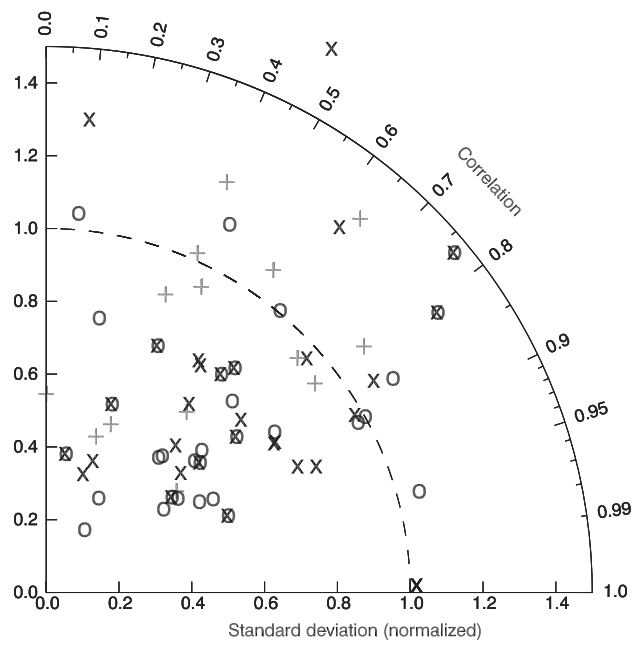

d)

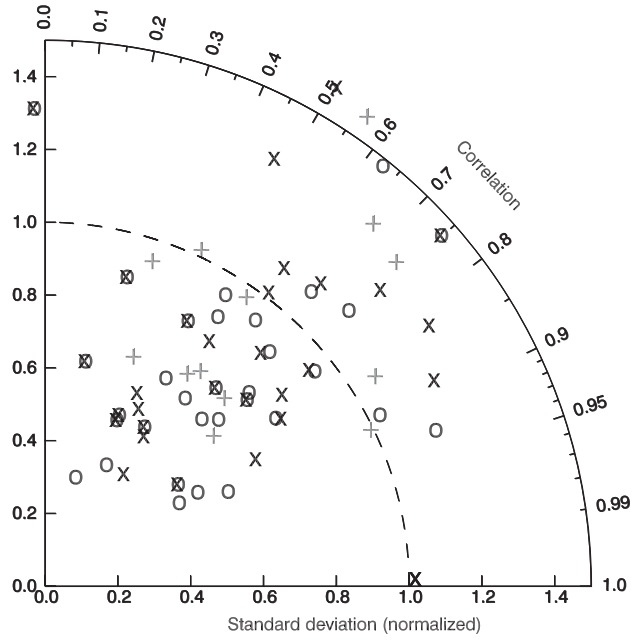

FIG. 3. Taylor diagram showing the representation of (a) Niño-3.4 SST for El Niño events, (b) north Australian SST for El Niño events, (c) Niño-3.4 SST for La Niña events, and (d) north Australian SST for La Niña events for all CMIP3 and CMIP5 models. The gray plus signs are the CMIP3 models, the black crosses are the CMIP5 models using the best (lowest RMSE for the same measure) ensemble member for each model, and the black circles are the ensemble mean for each CMIP5 model. Where the crosses and circles occur exactly together, there is only one ensemble member.

abilities to capture the observed SST evolution than the CMIP3 models. The CMIP5 models tend to lie closer to the observed standard deviation but have similar pattern correlation values. For the north Australian SST evolution during El Niño events (Fig. 3b), the CMIP5 models in general tend to underestimate the standard deviation (although there are a few that vastly overestimate it), whereas the CMIP3 models show a wider range of standard deviations. The Niño-3.4 SSTs during La Niña events (Fig. 3c) appear to be much better represented in general by the CMIP5 models than the CMIP3 models.

The SSTs in the north Australian region during El Niño and La Niña events (Figs. 3b,d) are still not as well represented as the Niño-3.4 SSTs. The CMIP5 models show a large spread in the standard deviations and the pattern correlations, and there is no clear indication that the models have improved much in their ability to capture this aspect of the tropical climate.

\section{Discussion and conclusions}

In this study, the link between ENSO and north Australian SSTs has been evaluated in the models participating in CMIP5 with a view to comparing them with the CMIP3 models evaluated in Catto et al. (2012). Considering the multimodel-mean results, the CMIP5 ensemble has smaller root-mean-square error values for the seasonal cycle of correlations and the composite event SST evolutions when compared to the CMIP3 multimodel mean. However, the CMIP5 models still show a wide range in their ability to represent both ENSO events themselves, and their relationship to 
north Australian SST. Most of the models fail to capture the strong seasonal cycle of correlation between the Niño3.4 and north Australian SSTs, with the exception of NorESM1-M and CNRM-CM5. The SST evolution in the Niño-3.4 region is generally better represented in the CMIP5 models. This may be due to the work of some modeling groups to improve ENSO variability in their models through improved convective parameterizations (e.g., Kim et al. 2011; Deser et al. 2012). Some improvements may also be associated with increases in horizontal resolution in both the atmosphere and ocean (e.g., in the GISS models), which would allow better simulation of features such as tropical instability waves (Guilyardi et al. 2004; Roberts et al. 2009). The corresponding north Australian SST evolution has not improved to the same extent however, with the models still showing a wide range of abilities to capture the observed patterns. It appears, therefore, that the models in general are still missing some underlying process or mechanism.

The larger number of ensemble members available from CMIP5 will be very useful when investigating the mechanism behind the strong links. The strong seasonal cycle of correlations between the two regions of interest is likely related to interactions between the SST anomalies and the seasonal cycle of mean zonal winds over the north Australian region (Hendon 2003), and this can be investigated more closely using the climate models that are able to represent the link. Gaining a deeper understanding of the physical mechanism behind the strong link between the SSTs in the Niño-3.4 region and to the north of Australia using these models is a vital next step for this work in order to elucidate the processes missing from the models that cannot capture the link.

Acknowledgments. This study was supported by the Australian Research Council through the Linkage Project Grant LP0883961, the Discovery Project Grant DP0877417, and the ARC Centre of Excellence for Climate System Science (Grant CE110001028). We acknowledge the World Climate Research Programme's Working Group on Coupled Modelling, which is responsible for CMIP, and we thank the climate modeling groups (listed in Table 1 of this paper) for producing and making available their model output. For CMIP, the U.S. Department of Energy's Program for Climate Model Diagnosis and Intercomparison provides coordinating support and led development of software infrastructure in partnership with the Global Organization for Earth System Science Portals. Finally, the authors thank the editor and three anonymous reviewers for their helpful comments and suggestions.

\section{REFERENCES}

AchutaRao, K., and K. R. Sperber, 2002: Simulation of the El Niño Southern Oscillation: Results from the Coupled Model Intercomparison Project. Climate Dyn., 19, 191-209.

$\longrightarrow$, and —, 2006: ENSO simulation in coupled oceanatmosphere models: Are the current models better? Climate Dyn., 27, 1-15.

Catto, J. L., N. Nicholls, and C. Jakob, 2012: North Australian sea surface temperatures and the El Niño-Southern Oscillation in observations and models. J. Climate, 25, 5011-5029.

Deser, C., A. S. Phillips, R. A. Tomas, Y. M. Okumura, M. A. Alexander, A. Capotondi, and J. D. Scott, 2012: ENSO and Pacific decadal variability in the Community Climate System Model version 4. J. Climate, 25, 2622-2651.

Donner, L. J., and Coauthors, 2011: The dynamical core, physical parameterizations, and basic simulation characteristics of the atmospheric component AM3 of the GFDL Global Coupled Model CM3. J. Climate, 24, 3484-3519.

Gent, P. R., and Coauthors, 2011: The Community Climate System Model version 4. J. Climate, 24, 4973-4991.

Griffies, S. M., and Coauthors, 2011: The GFDL CM3 coupled climate model: Characteristics of the ocean and sea ice simulations. J. Climate, 24, 3520-3544.

Guilyardi, E., and Coauthors, 2004: Representing El Niño in coupled ocean-atmosphere GCMs: The dominant role of the atmospheric component. J. Climate, 17, 4623-4629.

- H. Bellenger, M. Collins, S. Ferrett, W. Cai, and A. Wittenberg, 2012: A first look at ENSO in CMIP5. CLIVAR Exchanges, No. 58, International CLIVAR Project Office, Southampton, United Kingdom, 29-32.

Hendon, H. H., 2003: Indonesian rainfall variability: Impacts of ENSO and local air-sea interaction. J. Climate, 16, 1775-1790.

Kim, H.-J., K. Takata, B. Wang, M. Watanabe, M. Kimoto, T. Yokohata, and T. Yasunari, 2011: Global monsoon, El Niño, and their interannual linkage simulated by MIROC5 and the CMIP3 CGCMs. J. Climate, 24, 5604-5618.

Maury, P., F. Lott, L. Guez, and J.-P. Duvel, 2012: Tropical variability and stratospheric equatorial waves in the IPSLCM5 model. Climate Dyn., doi:10.1007/s00382-011-1273-0, in press.

Neale, R. B., J. H. Richter, and M. Jochum, 2008: The impact of convection on ENSO: From a delayed oscillator to a series of events. J. Climate, 21, 5904-5924.

Rayner, N. A., D. E. Parker, E. B. Horton, C. K. Folland, L. V. Alexander, D. P. Rowell, E. C. Kent, and A. Kaplan, 2003: Global analyses of sea surface temperature, sea ice, and night marine air temperature since the late nineteenth century. J. Geophys. Res., 108, 4407, doi:10.1029/2002JD002670.

Richter, J. H., and P. J. Rasch, 2008: Effects of convective momentum transport on the atmospheric circulation in the Community Atmosphere Model, version 3. J. Climate, 21, 1487-1499.

Roberts, M. J., and Coauthors, 2009: Impact of resolution on the tropical Pacific circulation in a matrix of coupled models. J. Climate, 22, 2541-2556.

Taylor, K. E., R. J. Stouffer, and G. A. Meehl, 2012: An overview of CMIP5 and the experiment design. Bull. Amer. Meteor. Soc., 93, 485-498.

Zhong, A. H., H. H. Hendon, and O. Alves, 2005: Indian Ocean variability and its association with ENSO in a global coupled model. J. Climate, 18, 3634-3649. 